\title{
Shaping of IPSCs by Endogenous Calcineurin Activity
}

\author{
Mathew V. Jones ${ }^{1}$ and Gary L. Westbrook ${ }^{1,2}$ \\ ${ }^{1}$ The Vollum Institute and ${ }^{2}$ Department of Neurology, Oregon Health Sciences University, Portland, Oregon 97201
}

Synaptic inhibition, mediated by $\mathrm{GABA}_{\mathrm{A}}$ receptors, regulates neuronal firing, influences coincidence detection (König et al., 1996), and can synchronize the output of neural circuits (Cobb et al., 1995). Although $\mathrm{GABA}_{\mathrm{A}}$ receptors can be modulated by phosphorylation, few studies have directly addressed the role of such modulation at synapses, where the nonequilibrium conditions of receptor activation are quite different from those often used to study $\mathrm{GABA}_{\mathrm{A}}$ receptors in vitro. Here we promoted endogenous phosphorylation by inhibiting specific phosphatases in rat hippocampal neurons and compared the effects on IPSCs with GABA $_{A}$ channel responses in outside-out patches. Brief and saturating GABA pulses ( $5 \mathrm{msec} ; 10 \mathrm{~mm}$ ) activated patch currents resembling the IPSC. Inhibition of calcineurin (protein phosphatase 2B), but not phosphatases 1 or $2 \mathrm{~A}$, produced a similar shortening of IPSC and patch responses, as did nonspecific inhibition of dephosphorylation using ATP $\gamma \mathrm{S}$ or high concentrations of intracellular phosphate. Calcineurin inhibition increased the microscopic ligand unbinding rate, which was measured using the competitive antagonist 2-(3-carboxypropyl)-3-amino-6-(4-methoxyphenyl)pyridazinium bromide, suggesting that the IPSC shortening was partly caused by destabilization of the ligand binding site. Calcineurin inhibition also increased the rate and extent of macroscopic receptor desensitization. These results show that endogenous regulation by kinases and calcineurin can produce substantial changes in the IPSC duration by altering the unbinding and gating kinetics of the $\mathrm{GABA}_{\mathrm{A}}$ receptor. Dynamic regulation of synaptic inhibition may thus allow for the tuning of circuit behavior at the level of individual inhibitory synapses.

Key words: $\mathrm{GABA}_{A}$ receptor; synapse; phosphorylation; modulation; kinetics; hippocampus
The IPSC results in a membrane hyperpolarization and resistive shunt that transiently reduces the likelihood of action potential firing. At synapses, receptors are activated by a brief, nonequilibrium exposure to a high concentration of GABA (Busch and Sakmann, 1990; Maconochie et al., 1994; Jones and Westbrook, 1995). The IPSC duration is thus primarily determined by the gating and unbinding kinetics of postsynaptic $\mathrm{GABA}_{\mathrm{A}}$ chloride channels (Maconochie et al., 1994; Jones and Westbrook, 1995). Modulation of $\mathrm{GABA}_{\mathrm{A}}$ channel kinetics is a valuable therapeutic tool, because it is the primary mechanism of action of the sedative benzodiazepines and most general anesthetics (Tanelian et al., 1993; Franks and Lieb, 1994). It is likely that the IPSC can also be endogenously regulated, as suggested by the prevalence of consensus phosphorylation sequences on cloned $\mathrm{GABA}_{\mathrm{A}}$ receptor subunits (for review, see Leidenheimer et al., 1991; Swope et al., 1992) and by the demonstration that $\mathrm{GABA}_{\mathrm{A}}$ channel function can be altered by site-specific phosphorylation (Moss et al., 1992; Krishek et al., 1994; Moss et al., 1995). Native GABA $_{\mathrm{A}}$ receptors are heteropentameric complexes and thus may contain a large number of phosphorylation sites per channel. However, the specific roles of these sites in inhibitory synaptic function remain unknown.

There is no obvious rule that determines whether phosphorylation increases or decreases $\mathrm{GABA}_{\mathrm{A}}$ receptor activity. For example, protein kinase A (Porter et al., 1990; Kano and Konnerth,

Received June 27, 1997; revised July 24, 1997; accepted July 28, 1997.

This work was supported by Grants F32 NS09716 (M.V.J.) and NS26494 (G.L.W.) from the National Institutes of Health. We thank Drs. Victor Derkach, Jeff Diamond, and Craig Jahr for a critical reading of a previous version of this manuscript and Jeff Volk for culture of hippocampal neurons.

Correspondence should be addressed to Dr. Mathew V. Jones, The Vollum Institute, Oregon Health Sciences University, L474, 3181 Southwest Sam Jackson Park Road, Portland, OR 97201.

Copyright (C) 1997 Society for Neuroscience $\quad 0270-6474 / 97 / 177626-08 \$ 05.00 / 0$
1992; Moss et al., 1992; Angelotti et al., 1993; Feigenspan and Bormann, 1994), protein kinase C (Sigel and Baur, 1988; Sigel et al., 1991; Kellenberger et al., 1992; Leidenheimer et al., 1992; Krishek et al., 1994; Lin et al., 1994), and protein kinase G (Leidenheimer, 1996; Robello et al., 1996) have all been reported either to increase or to decrease GABA responses. In addition, tyrosine kinase (Moss et al., 1995; Valenzuela et al., 1995) has been reported to enhance GABA responses, and calcium- and calmodulin-dependent protein kinase II (Wang et al., 1995) was shown to enhance IPSPs. Much of this complexity may result from differences in the receptor types under study and the existence of multiple regulatory mechanisms. However, an additional source of variability may arise from the different procedures used to elicit GABA responses. Most studies have used long, nonsaturating GABA applications. During such applications, the channel population is broadly distributed among unbound, open, and desensitized states (Jones and Westbrook, 1996), making it difficult to extract information about microscopic kinetics or their modulation by phosphorylation. In contrast, synaptic activation of $\mathrm{GABA}_{\mathrm{A}}$ receptors yields a relatively synchronized response of the channel population, consisting of rapid movement through the binding steps, and a subsequent relaxation through open and desensitized states until unbinding occurs (Jones and Westbrook, 1995, 1996). Such a situation places restrictions on the available modes of kinetic modulation (Mody et al., 1994) and simplifies the interpretation of changes in microscopic kinetics.

We studied the effects of endogenous phosphorylation mechanisms by comparing IPSCs with channel responses in excised patches. Promoting phosphorylation, by inhibiting calcineurin (protein phosphatase 2B) (for review, see Klee et al., 1988; Yakel, 1997), shortened the IPSC duration and enhanced macroscopic desensitization. Using rapid solution exchanges to approximate 

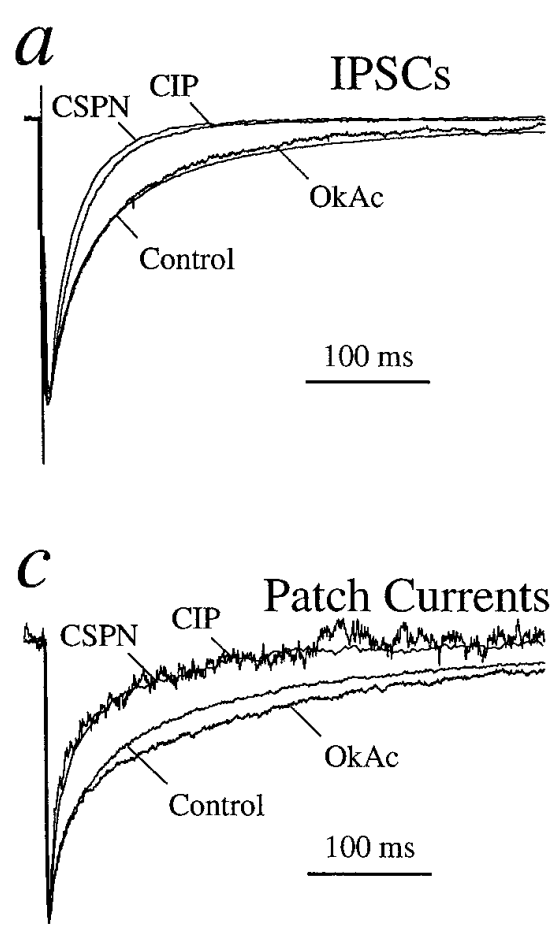

$b$

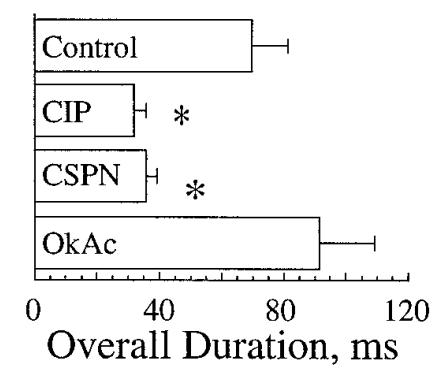

$d$

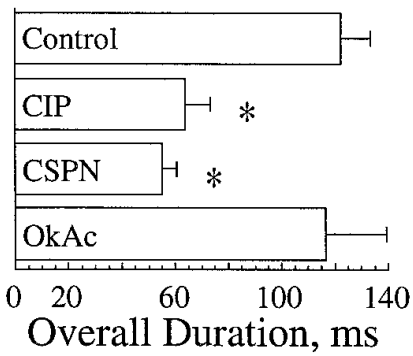

Figure 1. Inhibition of calcineurin shortens IPSC decay by altering $\mathrm{GABA}_{\mathrm{A}}$ channel kinetics. $a$, In the presence of CSPN $(500 \mathrm{nM})$ or CIP $(300 \mu \mathrm{M})$, IPSCs decayed approximately twice as fast as in control. OkAc $(1 \mu \mathrm{M})$ had no effect. $b$, Pooled data illustrate changes in the overall duration (defined as the weighted average of component durations, $\Sigma a_{\mathrm{i}} \tau_{\mathrm{i}}$, where $a_{\mathrm{i}}$ is the fractional amplitude, and $\tau_{\mathrm{i}}$ is the time constant of each component). The asterisks mark significant differences from control. $c, d$, Experiments are as described in $a$ and $b$, except recorded from outside-out patches pulled after $\geq 200 \mathrm{sec}$ of equilibration with the inhibitor in the whole-cell mode. Currents were evoked with $5 \mathrm{msec}$ pulses of $10 \mathrm{~mm}$ GABA. the synaptic activation of $\mathrm{GABA}_{\mathrm{A}}$ receptors, we show that this IPSC shortening results from a combination of two separable microscopic effects, a destabilization of the GABA binding site and a change in channel gating.

\section{MATERIALS AND METHODS}

Cell culture and recording. Cell culture methods were identical to those described previously (Jones and Westbrook, 1995). Whole-cell voltageclamp recordings $\left(\mathrm{V}_{\text {hold }}=-60 \mathrm{mV} ; 25^{\circ} \mathrm{C}\right)$ were obtained from neonatal rat hippocampal neurons maintained in "microdot" culture from 1 to 4 weeks. No systematic differences in $\mathrm{GABA}_{\mathrm{A}}$ receptor kinetics or modulation were observed with the time in culture. Pipette solutions contained (in mM): $144 \mathrm{KCl}, 1 \mathrm{CaCl}_{2}, 3.45 \mathrm{BAPTA}$ (free calcium buffered to $\sim 50 \mathrm{nM}$ ), $10 \mathrm{HEPES}$, and $5 \mathrm{Mg}_{2} \mathrm{ATP}, \mathrm{pH} 7.2$ and 315 mOsm. Phosphatase inhibitors and all other modulators were added to the pipette solution to give the final concentrations indicated. In some experiments, $\mathrm{Li}_{4} \mathrm{ATP} \gamma \mathrm{S}$ was substituted for $\mathrm{Mg}_{2} \mathrm{ATP}$. The extracellular solution contained (in $\mathrm{mM}$ ): $140 \mathrm{NaCl}, 2.8 \mathrm{KCl}, 1 \mathrm{MgCl}_{2}, 1.5$ $\mathrm{CaCl}_{2}, 10$ HEPES, and $10 \mathrm{D}$-glucose, $\mathrm{pH} 7.4$ and $325 \mathrm{mOsm}$. CNQX $(10 \mu \mathrm{M})$ and strychnine $(1 \mu \mathrm{M})$ were present in all recordings. GABA $(10 \mathrm{~mm})$ was added to this solution and applied to outside-out patches using a piezoelectric-driven solution switching system. The solution exchange time was $<1 \mathrm{msec}$, measured by the $10-90 \%$ rise and fall times of the liquid junction current at the open pipette tip after each recording. Currents were recorded with an Axopatch 1C amplifier (Axon Instruments, Foster City, CA), filtered at $1-5 \mathrm{kHz}$ using the four pole Bessel filter of the amplifier, and sampled at greater than or equal to twice the filter frequency using a TL-125 analog-digital interface and AxoBASIC software (Axon Instruments). After achieving the whole-cell mode, we evoked autaptic IPSCs by $0.5 \mathrm{msec}$ voltage steps to $+40 \mathrm{mV}(0.2 \mathrm{~Hz})$. Whole-cell recordings were maintained for $\geq 200 \mathrm{sec}$ before pulling patches, whether or not phosphatase inhibitors were present. Unless stated otherwise, data are presented as mean \pm SEM. Results from recordings using phosphatase inhibitors were deemed to be significantly different from separate control recordings at the $p \leq 0.05$ level by unpaired two-tailed $t$ tests, by $F$ tests, or by one-way ANOVA followed by $t$ tests when several groups were compared. Cyclosporin A (CSPN) and okadaic acid (OkAc) were obtained from Calbiochem (La Jolla, CA), calcineurin inhibitory peptide (CIP) from Bachem California (Torrance, CA), and 2-(3-carboxypropyl)-3amino-6-(4-methoxyphenyl)pyridazinium bromide (SR-95531) from
Research Biochemicals (Natick, MA). All other chemicals were from Sigma (St. Louis, MO).

Kinetic modeling and variance analysis. To examine the kinetics across a potentially heterogeneous population of patch responses, we constructed a grand average of currents from all patches under each of four experimental conditions. The conditions were either brief $(5 \mathrm{msec})$ or long (100 msec) pulses of $10 \mathrm{~mm}$ GABA, using either control or CSPNcontaining pipette solutions. A kinetic model was then fit to the averaged control responses using a least-squares procedure, with rates allowed to vary within ranges similar to those found previously (see Fig. 4a, inset) (Jones and Westbrook, 1995). The best-fitting rates were fixed, and fitting was repeated to model the effects of CSPN with one free parameter $\left(k_{\text {off }}\right)$. Because CSPN produced two separable effects, the best value of $k_{\text {off }}$ was fixed, and a third round of fitting was performed with a second free parameter $(\alpha)$. Other choices of free parameters were also examined but gave inferior fits.

To perform variance analysis (Sigworth, 1980), we applied a series of GABA pulses $(5 \mathrm{msec} ; 10 \mathrm{~mm})$ to outside-out patches at $5 \mathrm{sec}$ intervals. The ensemble mean current $(I)$ and variance $\left(\sigma^{2}\right)$ were calculated for each data point using local averaging to minimize distortion caused by response rundown. The mean current was divided into 100 equally sized bins, and the corresponding variances were averaged. Plots of binned variance versus current were fit with the equation: $\sigma^{2}=i I-I^{2} N^{-1}$, where $i$ is an estimate of the single channel current, and $N$ is an estimate of the number of channels. For display, individual plots were normalized to the fitted maximum variances [at open probability $\left(P_{\mathrm{o}}\right)=0.5$ ] and amplitudes (at bin 100) and were averaged together (10 in control and 6 in CSPN). The curves that best fit these normalized data are shown below (see Fig. $4 c$ ). The average parameters from fitting each plot separately are given in the text.

\section{RESULTS}

\section{Inhibition of calcineurin shortens IPSCs and brief pulse responses to GABA}

Autaptically evoked IPSCs displayed a rapid rising phase $(\sim 1$ msec) and a prolonged biexponential decay (Fig. 1a). To simplify comparisons between treatments, we also characterized biexponential decays using the overall duration (i.e., the weighted average of fast and slow decay components in milliseconds). We first examined the effect of phosphatase inhibitors on the IPSC. When 
$a$

\section{IPSCs}

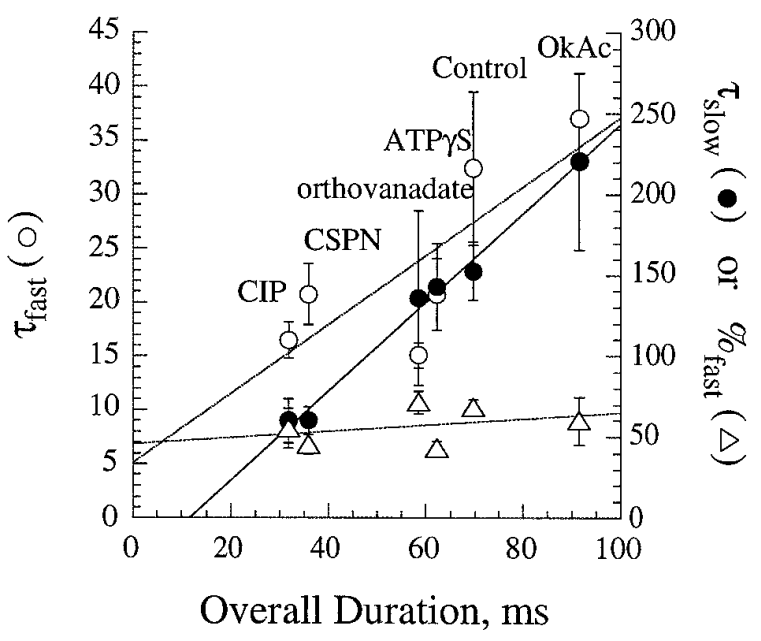

$b$

\section{Patch Currents}

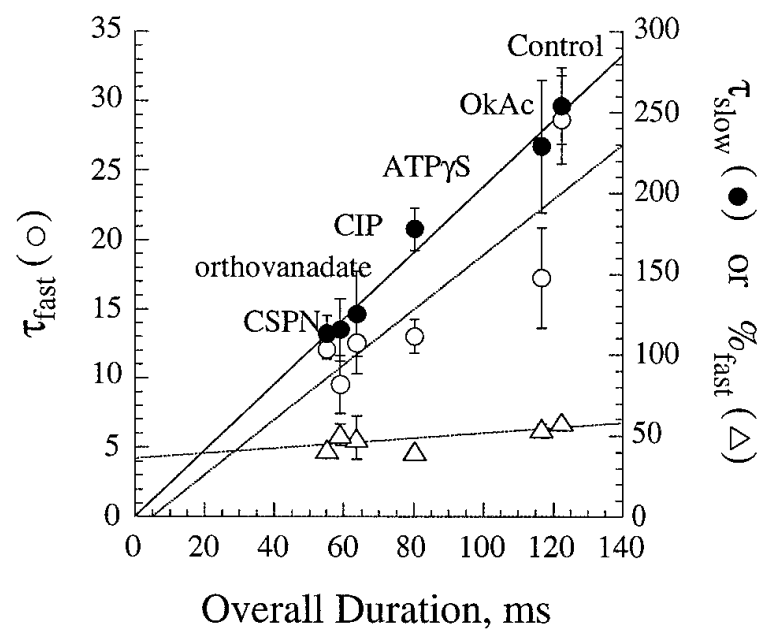

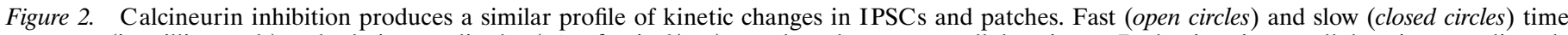

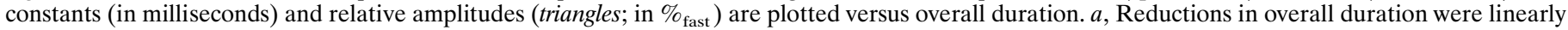

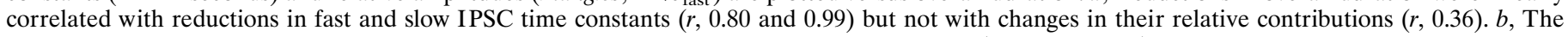

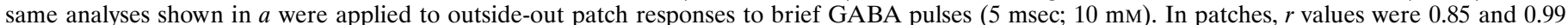
for fast and slow time constants and 0.69 for $\%$ fast

loaded into neurons via the recording pipette, the calcineurin inhibitors CSPN (500 nM) and CIP (300 $\mu \mathrm{M}$; Hashimoto et al., $1990)$ reduced the overall IPSC duration from $70 \pm 11 \mathrm{msec}$ (mean \pm SEM; $n=11)$ in control to $36 \pm 6 \mathrm{msec}(n=3)$ and $32 \pm 4 \mathrm{msec}(n=5)$, respectively (Fig. 1a,b). Loading pipettes with a concentration of OkAc $(1 \mu \mathrm{M})$ that inhibits protein phosphatases (PP) 1 and 2A but not calcineurin (Bialojan and Takai, 1988) had no effect, whereas a higher concentration $(5 \mu \mathrm{M})$ that inhibits calcineurin shortened the IPSC duration to $45 \pm 5 \mathrm{msec}$ $(n=6$; data not shown).

Brief and saturating pulses of GABA (5 msec; $10 \mathrm{~mm})$ to outside-out patches evoked responses that resembled the IPSC (Fig. 1c,d), decaying with an overall duration of $122 \pm 11 \mathrm{msec}$ $(n=13)$. As with the IPSC, CSPN and CIP shortened patch current decay to $55 \pm 5 \mathrm{msec}(n=12)$ and $63 \pm 10 \mathrm{msec}(n=4)$, respectively. OkAc ( $1 \mu \mathrm{M} ; n=5)$ had no effect, whereas OkAc at a higher concentration $(5 \mu \mathrm{M})$ shortened patch currents to $51 \pm$ $23 \mathrm{msec}(n=5$; data not shown). The $10-90 \%$ rise times of IPSCs were not measured because of the overlapping stimulus artifact. However, CSPN did not alter the rise time of patch currents (control, $1.2 \pm 0.5 \mathrm{msec}$; CSPN, $1.3 \pm 0.6 \mathrm{msec}$ ). Although IPSCs and patch currents were similar, the somewhat slower decay of patch currents (attributable solely to a longer slow component) may have been caused by the removal of endogenous enzymes or the cytoskeleton after patch excision (Whatley et al., 1994). Together, our results suggest that dephosphorylation of Ser or Thr residues of the $\mathrm{GABA}_{\mathrm{A}}$ receptor or an associated protein results in long duration IPSCs. In addition, endogenous calcineurin is able to hydrolyze these residues, whereas PP1 or PP2A are not. This apparent specificity could be attributable either to true specificity for substrates or to differential localization of the enzymes. Including orthovanadate $(100 \mu \mathrm{M})$ in the pipette solution also reduced overall patch current duration to $59 \pm 4 \mathrm{msec}$ ( $n=7$; Fig. 2), raising the possibility that endogenous tyrosine phosphatase activity can prolong IPSCs.
The effects of calcineurin inhibitors were apparent within a few seconds of establishing the whole-cell configuration and remained stable throughout the recording. It is therefore likely that the effective rates of endogenous phosphorylation and dephosphorylation are both high (i.e., the phosphate turnover time is short). If the rate of phosphorylation were slow, one would expect a slow onset reflecting the slow accumulation of phosphoprotein. Conversely, if dephosphorylation were slow, one would expect little effect of calcineurin inhibition. This rapid onset precluded direct measurement of changes in current amplitude within a single recording. However, there were no significant differences in IPSC or patch current amplitude between control recordings and those with CSPN. The estimated peak channel open probability was also unaffected by CSPN (see below). The main action of calcineurin inhibition on hippocampal inhibitory synapses was therefore to shorten IPSCs by speeding GABA $_{\mathrm{A}}$ channel deactivation.

\section{Modulation depends on endogenous phosphorylation mechanisms}

Because kinases and phosphatases compete for protein substrates, the concentrations, activities, and localization of enzymes in relation to the substrate determine the equilibrium level of phosphorylation. Therefore, it is likely that calcineurin inhibition shortened IPSCs and patch currents by shifting the equilibrium to favor phosphorylation of the substrate by endogenous kinases. To confirm this idea, and to rule out phosphorylation-independent mechanisms, we directly shifted the equilibrium in favor of the phosphorylated substrate by loading pipettes with either ATP $\gamma \mathrm{S}$ or inorganic phosphate. ATP $\gamma \mathrm{S}$ donates a thiophosphate group in kinase-mediated reactions that resists hydrolysis by phosphatases (Eckstein, 1985). In the presence of $\mathrm{Li}_{4} \mathrm{ATP} \gamma \mathrm{S}(100 \mu \mathrm{M})$, the overall duration of patch currents was shortened to $80 \pm 6 \mathrm{msec}$ $(n=9)$, mimicking the action of calcineurin inhibition. Similarly, inorganic phosphate, the product of phosphatase-mediated hydrolysis, should bias the equilibrium in the direction of the phos- 
phoprotein substrate. Loading pipettes with $25 \mathrm{~mm}$ potassium phosphate also mimicked the action of calcineurin inhibition, shortening patch current decay to $71 \pm 8 \mathrm{msec}(n=8$; data not shown). These effects were caused by the phosphate groups rather than by secondary effects, because neither lithium chloride (20 $\mathrm{mm} ; n=4)$ nor GTP $\gamma \mathrm{S}(100 \mu \mathrm{M} ; n=6)$ significantly shortened patch current durations.

\section{Parallel shortening of IPSC and patch current deactivation time constants}

Recent evidence suggests that the biexponential decay of IPSCs and patch currents arises from the relaxation of GABA-bound channels back toward unbound states via multiple visits to open and desensitized states (Maconochie et al., 1994; Jones and Westbrook, 1995, 1996). In general, the relative frequency of visits to a given set of states is proportional to the amplitude of a decay component, whereas the time spent in those states influences the component time constant. Linear regression of the time constants and fractional amplitudes versus overall duration revealed that the phosphorylation-induced shortening of IPSCs and patch currents was strongly correlated with reductions in time constants but not with changes in their relative amplitudes. Figure 2 shows a graphical presentation of the changes in time constants $\left(\tau_{\text {fast }}\right.$, open circles; $\tau_{\text {slow }}$, closed circles $)$ and the relative contribution of the fast component ( $\%_{\text {fast }}$, triangles $)$ caused by promoting phosphorylation. In control conditions, IPSCs decayed with time constants of $32 \pm 7$ and $152 \pm 18 \mathrm{msec}$ and with the fast component comprising $68 \pm 4 \%$ of the amplitude $(n=11)$. In the presence of CSPN, IPSC components were $20 \pm 6$ and $60 \pm 17^{*}$ msec, with $45 \pm 12 \%$ of current carried by the fast component ( $n=3$; asterisks denote $p \leq 0.05$ compared with control). For CIP, components were $16 \pm 2 *$ and $60 \pm 14^{*}$ msec, with $55 \pm$ $13 \%$ in the fast component $(n=5)$. Okadaic acid $(1 \mu \mathrm{M} ; n=5)$ had no effect on any of the three parameters. It is possible that factors such as an imperfect space clamp of distant synapses or asynchrony of transmission could have masked changes in $\tau_{\text {fast }}$ for CSPN because, in patches, CSPN and CIP shortened both time constants (Fig. $2 b$ ). Patch currents in control decayed with components of $29 \pm 3$ and $253 \pm 24 \mathrm{msec}$, with $58 \pm 2 \%$ in the fast component $(n=13)$. For CSPN, components were $12 \pm 1^{*}$ and $113 \pm 11 *$ msec, with $41 \pm 2 \% *$ fast $(n=12)$. For CIP, components were $12 \pm 2 *$ and $125 \pm 26^{*}$ msec, with $48 \pm 13 \%$ fast $(n=$ 4); and for OkAc, components were $17 \pm 4^{*}$ and $229 \pm 41 \mathrm{msec}$, with $54 \pm 3 \%$ fast $(n=5)$.

The changes in time constants without a change in their relative amplitudes suggest that, after phosphorylation, channels continue to enter the same active states with the same relative frequencies as in control but tend to spend less time in those states. The profile of kinetic changes in patch currents was similar to that for IPSCs, suggesting that similar or identical mechanisms are responsible for shortening both types of current. Therefore, shortening of the IPSC results from changes in the kinetics of the $\mathrm{GABA}_{\mathrm{A}}$ receptor rather than from altered GABA uptake or chloride-handling mechanisms.

\section{Phosphorylation increases the microscopic GABA unbinding rate}

The fast component of $\mathrm{GABA}_{\mathrm{A}}$ channel deactivation represents a series of oscillations between closed and open channel states (a burst), whereas the slow component consists of a series of bursts separated by visits to long-lived desensitized states (a cluster) (Jones and Westbrook, 1995, 1996). An economical explanation for the changes in time constants illustrated in Figure 2 would therefore involve a phosphorylation-induced increase in a single transition rate that shortened the time spent in bursts and clusters to a similar extent. Because both burst and cluster lengths depend on the duration of receptor occupancy (Jones and Westbrook, 1995), we first considered the hypothesis that phosphorylation increases the unbinding rate of GABA. To estimate changes in the unbinding rate, we used the competitive antagonist SR-95531 $\left(\mathrm{IC}_{50}=160 \mathrm{~nm}\right)$ (Hamann et al., 1988) because, unlike GABA, measurement of antagonist unbinding should not be confounded by movement through open or desensitized states (but see Ueno et al., 1997). Classical pharmacological analysis shows that SR95531 causes parallel right-shifts of the GABA dose-response curve, diagnostic for competitive antagonism (Hamann et al., 1988). Its action is also modified by point mutations in the putative GABA binding site (Ueno et al., 1997). Therefore, the unbinding kinetics of SR-95531 should reflect interactions with the same regions occupied by GABA. Patches were preequilibrated in a saturating concentration of SR-95531 (10 $\mu \mathrm{M})$, and the time course of SR-95531 unbinding was revealed by applying pulses of $10 \mathrm{~mm}$ GABA at various intervals after removal of SR-95531. Figure 3, $a$ and $b$, shows that the current produced by GABA (i.e., the fraction of channels from which SR-95531 had unbound) increased with the interval after removal of SR-95531. In control conditions, SR-95531 unbound with a time constant of $105 \pm 29 \mathrm{msec}$ (Fig. $3 b ; n=4$; fitted parameter \pm error of fit). The unbinding time constant was reduced to $34 \pm 4$ msec by CSPN ( $n=4 ; F$ test) (Motulsky and Ransnas, 1987). Although assignment of the corresponding microscopic rate constants requires knowledge of the number and cooperativity of binding sites, these data strongly suggest that phosphorylation induces a conformational change that directly destabilizes ligand attachment. The phosphorylation-dependent shortening of GABA-activated patch currents can be explained on the basis of the SR-95531 unbinding experiment by postulating that destabilization of the binding site affects SR-95531 and GABA similarly. For example, the kinetic model (Fig. 4a, inset) used to simulate control patch currents (Fig. 4a, $i$ ) also predicted the shortening of deactivation by CSPN when the GABA unbinding rate was increased in direct proportion to the CSPN-induced increase in SR-95531 unbinding (approximately threefold; Fig. 4a, ii).

\section{Phosphorylation also enhances macroscopic desensitization}

The data presented thus far mainly address the kinetics that occur when the channel is allowed to relax from the bound to the unbound state (deactivation) after a brief GABA exposure. Our analysis indicates that the ligand unbinding process is modulated by phosphorylation and that this effect contributes to the shortening of deactivation. However, channel opening and desensitization kinetics also participate in shaping deactivation (Jones and Westbrook, 1995, 1996). We therefore examined the kinetics that occur while GABA is fully bound by using long and saturating GABA applications. During a $100 \mathrm{msec}$ exposure to $10 \mathrm{~mm}$ GABA, CSPN increased the rate and extent of macroscopic desensitization (Fig. $4 b$, dots). CSPN reduced the desensitization time constant from $44 \pm 7 \mathrm{msec}(n=7$; approximated by a single exponential plus a constant) to $17 \pm 0.7 \mathrm{msec}(n=3)$ and reduced the fitted steadystate current from 58 to $32 \%$ of the peak. Therefore, in addition to an increase in the GABA unbinding rate, phosphorylation also 
$a$

Open Tip

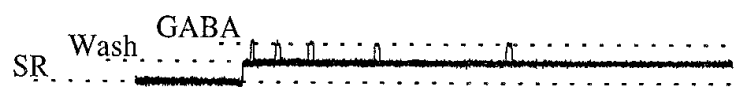

Control

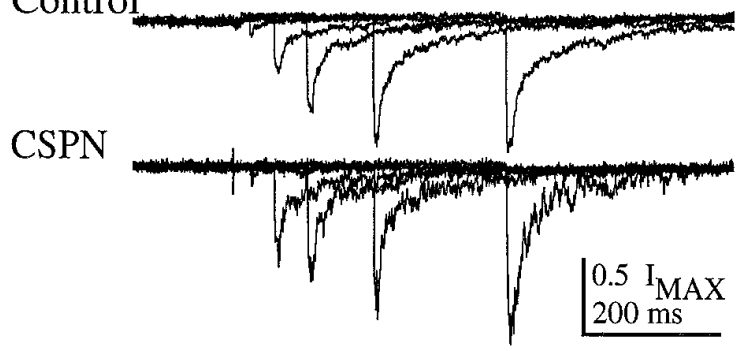

$b$

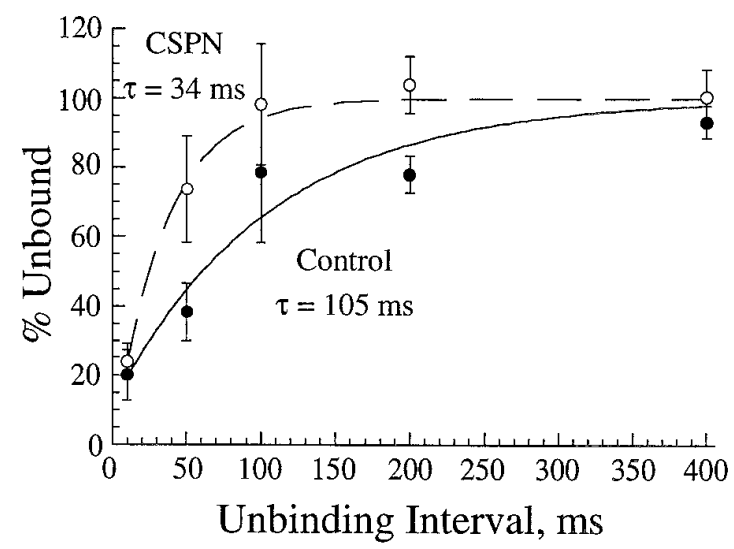

Figure 3. Inhibition of calcineurin increases the rate of ligand unbinding from the $\mathrm{GABA}_{\mathrm{A}}$ receptor. $a$, After a $750 \mathrm{msec}$ pre-equilibration with the competitive antagonist SR-95531 $(S R ; 10 \mu \mathrm{M})$, the fraction of unbound channels (i.e., the percentage of maximum current) was tested with GABA pulses at various unbinding intervals. Top, The time course of solution exchanges was measured at the open pipette tip at the end of the experiment. Middle, Increasing the SR-95531 unbinding interval resulted in larger test currents. Bottom, With CSPN (500 nM) in the patch pipette, test currents recovered to full amplitude more rapidly relative to control after SR-95531 removal. $b$, A plot of the percentage of channels unbound versus the interval after SR-95531 removal shows that CSPN accelerated the unbinding of SR-95531. Single exponential functions were fitted to the data, and no correction was made for the few channels that unbind SR-95531 during the test pulse itself. The SR-95531-unbinding time courses in control and CSPN are significantly different at the $p \leq 0.05$ level, as determined by an $F$ test (Motulsky and Ransnas, 1987).

alters the gating of GABA-bound channels, and these two effects are experimentally distinguishable.

Because occupancy of the open state protects the channel from desensitization, the CSPN-induced enhancement of macroscopic desensitization could occur through a reduction in the probability of initially reaching the open state [i.e., by slowing rates of opening $(\beta)$ or resensitization $(r)$ or by speeding rates of desensitization $(d)$; Figure $4 a$, inset]. Alternatively, macroscopic desensitization could be increased by a reduction in the duration of the open state. However, CSPN did not significantly alter the maximum $P_{\mathrm{o}}$, as estimated by nonstationary variance analysis (Fig. $4 c$, normalized values shown; see Materials and Methods), suggesting that the channel follows its normal path to the open state. This result was anticipated by the absence of a change in the relative amplitudes of deactivation components (Fig. 2). The average parameters from non-normalized data were $i=2.6 \pm 0.5 \mathrm{pA}, N=$ $417 \pm 291$, and $P_{\mathrm{o}}=0.70 \pm 0.06(n=10)$ in control conditions and $i=2.2 \pm 0.45 \mathrm{pA}, N=485 \pm 351$, and $P_{\mathrm{o}}=0.56 \pm 0.11(n=$ 6) for CSPN. An approximately twofold reduction in $P_{\mathrm{o}}$ would have been necessary to account for the CSPN-induced increase in desensitization. Such a change would have been statistically detectable given the SEM in our $P_{\mathrm{o}}$ estimates. Conversely, the desensitization and deactivation kinetics in the presence of CSPN are reasonably well predicted by reducing the mean channel open time (in addition to increasing the GABA unbinding rate) (Fig. $4 b, i i i)$. Except for a very high concentration (5 mM) of ATP $\gamma \mathrm{S}$, none of the modulators used in this study significantly altered the kinetics of recovery from paired-pulse desensitization (data not shown). The enhancement of macroscopic desensitization during saturating GABA pulses therefore seems to result from an increase in the channel closing rate and not from a change in desensitization per se.

\section{DISCUSSION}

We used a kinetic approach to study the effects of phosphorylation and dephosphorylation on synaptic inhibition. Our data show that promoting phosphorylation by endogenous kinases shortened the IPSC by altering the underlying kinetics of $\mathrm{GABA}_{\mathrm{A}}$ receptors. Inhibition of calcineurin was particularly effective in producing these alterations. We resolved two separable effects of phosphorylation: destabilization of the ligand/receptor interaction and enhanced macroscopic desensitization probably mediated by a reduction in channel open time.

\section{Two discrete mechanisms of IPSC regulation}

When $\mathrm{GABA}_{\mathrm{A}}$ channels are activated by agonist, the kinetics of the response are influenced by many simultaneously occurring processes: binding and unbinding, opening and closing, and desensitization and resensitization. The shape of the response cannot usually be related directly to any individual transition. We were, however, able to isolate the unbinding process of the competitive antagonist SR-95531, which does not activate channel gating or (we presume) desensitization, and found that it was increased approximately threefold by CSPN. This result suggests that phosphorylation at an intracellular locus produced a structural change that was transmitted to the extracellular binding site. This structural change also seems to destabilize the attachment of GABA.

A second effect of phosphorylation was revealed by effectively removing the contributions of the binding and unbinding transitions with long and saturating GABA applications. Under these conditions, CSPN increased the rate and extent of current decay during the GABA pulse. This increase in macroscopic desensitization did not seem to be caused by an increase in microscopic desensitization per se, because the peak open probability of GABA responses was not altered and because the best model fits were obtained by reducing the channel open time. It should be noted, however, that if desensitization proceeds directly from the open state, increasing microscopic desensitization would also shorten the open time. The precise connectivity of channel states remains unknown, but the model in Figure 4 has been successful at reproducing a wide range of experimental observations (Jones 

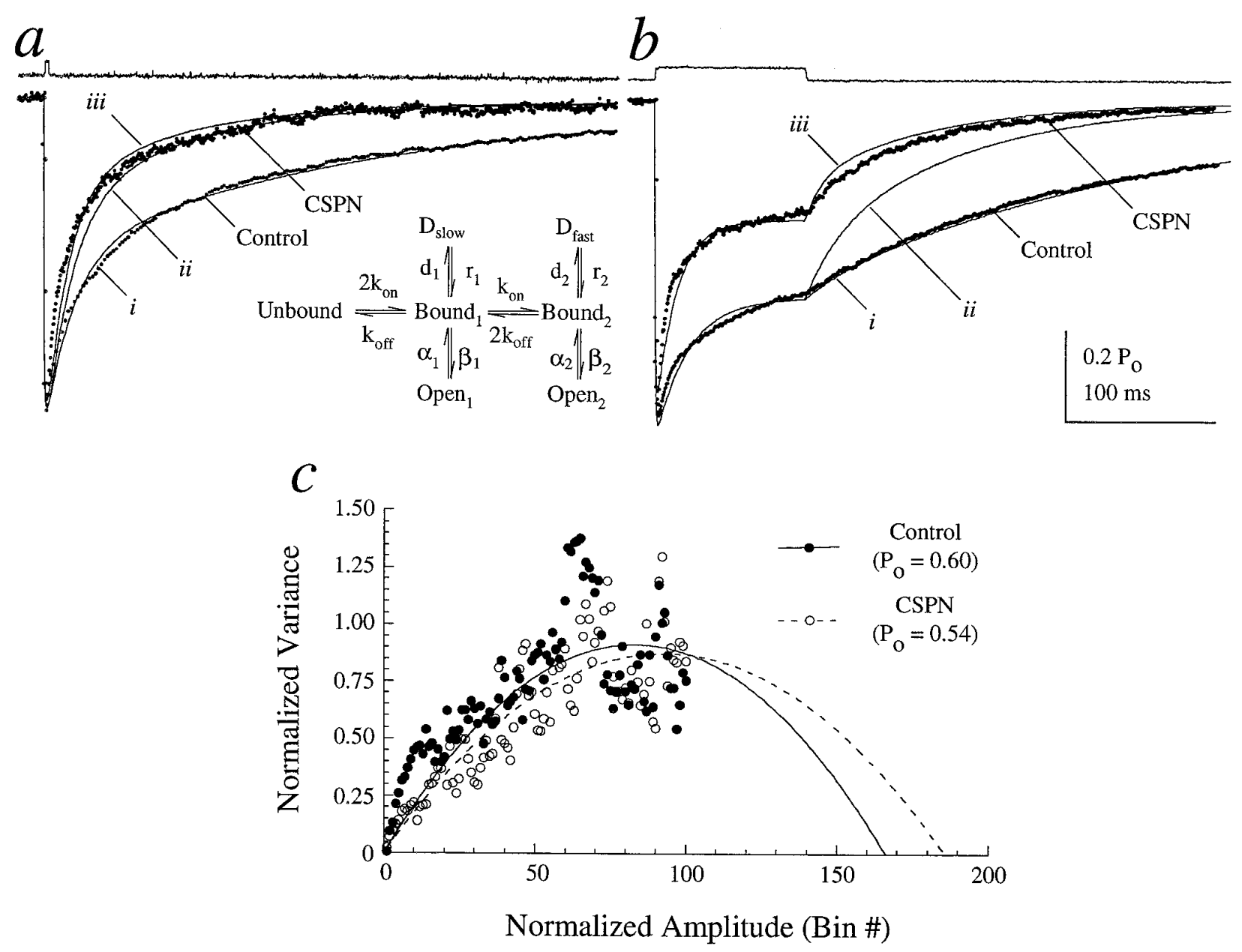

Figure 4. Inhibition of calcineurin alters both GABA-unbinding and channel-gating kinetics. $a$, A kinetic model (Jones and Westbrook, 1995) (inset, see Materials and Methods) was allowed to fit the grand average response to a brief GABA pulse (5 msec; $10 \mathrm{~mm})$ under control conditions $(i)$. The fitted rates were $k_{\text {on }}=3 \mu \mathrm{M}^{-1} \mathrm{sec}^{-1}$ and (in sec ${ }^{-1}$ ): $k_{\text {off }}=120, \beta_{1}=200, \alpha_{1}=1111, \beta_{2}=2700, \alpha_{2}=142, d_{1}=13, r_{1}=0.13, d_{2}=740$, and $r_{2}=27$. The CSPN-induced acceleration of current decay could be described by increasing the GABA unbinding rate threefold (ii, $\left.k_{\text {off }}=370\right)$, as predicted by the SR-95531 unbinding experiments (Fig. 2). A small improvement in the fit occurred with an additional shortening of the mean channel open time [iii, the sum of squared errors was reduced by $16 \%$ for $\left.\alpha_{2}=176\right] . b$, The model was allowed to fit the grand average control response to a long and saturating GABA pulse ( $100 \mathrm{msec} ; 10 \mathrm{~mm})\left(i, k_{\text {off }}=100, \beta_{2}=2800, d_{2}=630\right.$, and the other rates are as given in $a$ above). A threefold increase in the unbinding rate $\left(i i, k_{\text {off }}=310\right)$ accelerated deactivation but could not account for the increased macroscopic desensitization caused by CSPN, whereas adding a reduction in mean open time (iii, $\alpha_{2}=310$ ) accounted for both the desensitization and deactivation in CSPN. The SSE was 30 and $92 \%$ higher when the rates $d_{2}$ or $r_{2}$, respectively, were varied instead of $\alpha_{2}$ (data not shown). $c$, A plot of current versus variance shows no significant difference in peak open probability between control and CSPN (see Materials and Methods).

and Westbrook, 1995, 1996). We therefore favor a shortening of open time over increased desensitization to account for the data.

Regardless of the model chosen, the enhanced macroscopic desensitization represents an effect on channel kinetics independent of the change in GABA unbinding. In light of the large number of phosphorylation sites likely to exist per channel complex and the variety of kinases known to phosphorylate the receptor, it is possible that the independent effects of destabilizing GABA attachment and destabilizing the open state are mediated by independent kinases. Such an arrangement would allow for considerable flexibility in shaping inhibition (Jones and Westbrook, 1996). For example, increasing GABA unbinding alone would shorten IPSCs but also reduce the accumulation of channels in desensitized states during high frequency stimulation (similar to $\beta$-Ala and taurine responses in Jones and Westbrook, 1995; Zhu and Vicini, 1997). Conversely, reducing the open time alone would shorten IPSCs but increase accumulation in desensitized states during repetitive stimuli.

\section{Rationale for the kinetic approach using native receptors}

Previous studies are nearly evenly divided as to whether phosphorylation increases or decreases $\mathrm{GABA}_{\mathrm{A}}$ receptor activity (Sigel and Baur, 1988; Porter et al., 1990; Sigel et al., 1991; Kano and Konnerth, 1992; Kellenberger et al., 1992; Leidenheimer et al., 1992; Moss et al., 1992; Angelotti et al., 1993; Feigenspan and Bormann, 1994; Krishek et al., 1994; Lin et al., 1994; Leidenheimer, 1996; Robello et al., 1996). This variety of results probably arises both from biological and methodological factors. Biological variability can stem from differences in the receptor subunit combination, in the activities of kinases and phosphatases present, and in their cellular localization relative to the receptor. These complications may be minimized somewhat by studying receptors transfected into heterologous expression systems. However, it is not always clear that the behavior observed in such systems is typical of that in the native neuronal environment. In 
neither case are the subunit stoichiometry or the receptor regulation completely defined. Here, we focused on the behavior of native channels at functional synapses. Although this focus limits our knowledge of the receptor composition and the molecular identity of the phosphorylation sites involved, it ensures that our observations reflect an intact physiological environment.

The methodological sources of variability most relevant for this discussion are the kinetic conditions of receptor activation and the parameters of the response being measured. For example, use of low GABA concentrations causes the binding steps to be rate-limiting in the response, whereas use of high GABA concentrations yields kinetics dominated by transitions between open and closed or desensitized states (Jones and Westbrook, 1996). Similarly, brief and long GABA pulses emphasize different kinetic behaviors (Jones and Westbrook, 1995). Thus, if phosphorylation affects a particular kinetic transition, the effect observed will depend strongly on whether that transition is emphasized or masked by the experimental conditions. Recent estimates suggest that the GABA concentration in the synapse reaches several hundred micromolar at its peak and decays within milliseconds (Busch and Sakmann, 1990; Maconochie et al., 1994; Jones and Westbrook, 1995). Synaptic stimulation is thus a useful "method" for producing GABA applications with a relatively stereotyped concentration and time course (for another opinion, see Frerking et al., 1995; Frerking and Wilson, 1996).

\section{The roles of calcineurin and kinases in regulating synaptic inhibition}

Inhibition of calcineurin shortened IPSCs and patch currents in parallel, suggesting that the changes were caused by phosphorylation of the $\mathrm{GABA}_{\mathrm{A}}$ channel itself or a tightly associated protein rather than a soluble regulatory factor. We used phosphatase inhibitors, rather than exogenous enzymes, because the resulting effects reflect the endogenous activity of both kinases and phosphatases. The observation that orthovanadate also shortened patch current deactivation suggests that serine/threonine and tyrosine kinases may act in concert to regulate IPSC kinetics. Although we did not directly address the role of particular kinases, the kinetic methods used here can easily be adapted to the study of kinases in the future.

In our experiments, calcineurin inhibitors were allowed to equilibrate in the whole-cell mode for a few minutes before patches were excised. The observed shortening of patch responses could therefore be attributable to soluble kinases active during the whole-cell mode or to membrane-associated kinases retained in the patch after excision. Interestingly, a large fraction of cellular calcineurin is associated with the plasma membrane (for review, see Yakel, 1997). This raises the possibility that the slower decay of patch currents than of IPSCs may be caused by retention of calcineurin in patches after competing kinases have been removed by excision. At the intact synapse, calcineurin activity may provide a calcium-dependent reset mechanism for restoring long duration IPSCs after they have been shortened by kinases. For example, it has been proposed that calcium transients mediate the IPSC prolongation caused by the volatile anesthetic halothane (Mody et al., 1991) and the long-lasting IPSC prolongation after dendrotomy of dentate granule cells (Soltesz and Mody, 1995). Alternatively, background calmodulin-independent calcineurin activity (Klee et al., 1988) could maintain long duration IPSCs until overcome by the activation of kinases. Consistent with this latter idea, our results show that calcineurin and kinases can be active at "resting" calcium levels (i.e., buffered to $\sim 50 \mathrm{~nm}$ with BAPTA).

Because our experiments focused on synaptic stimulation and GABA applications designed to approximate the GABA transient at the synapse, it is difficult to compare this study directly with those using qualitatively different protocols. However, our results contrast with a recent report that calcineurin inhibition reduces desensitization of whole-cell $\mathrm{GABA}_{\mathrm{A}}$ responses $(100 \mu \mathrm{M}$ GABA; 10 sec applications) (Martina et al., 1996). This discrepancy may perhaps be resolved by our finding that the GABA unbinding rate was increased threefold by CSPN. Such a reduction in the affinity for GABA would reduce the receptor occupancy at $100 \mu \mathrm{M}$ from $\sim 80 \%\left(\mathrm{EC}_{50}=19 \mu \mathrm{M}\right.$; M. V. Jones, Y. Sahara, J. A. Dzubay, and G. L. Westbrook, unpublished observations) to $\sim 50 \%$, concurrently reducing the apparent desensitization (Jones and Westbrook, 1996). Two other studies have shown that calcineurin, activated by calcium entering through NMDA receptors, can reduce whole-cell $\mathrm{GABA}_{\mathrm{A}}$ responses $(\leq$ $200 \mu \mathrm{M}$ GABA; $25 \mathrm{msec}-10 \mathrm{sec}$ ) (Stelzer and Shi, 1994; Chen and Wong, 1995). At present, we have no satisfactory explanation for the apparent difference between those results and our own.

\section{Implications for local circuit function}

The profound cognitive effects of drugs that prolong $\mathrm{GABA}_{\mathrm{A}}$ receptor-mediated IPSCs (e.g., benzodiazepines, barbiturates) and the convulsant actions of $\mathrm{GABA}_{\mathrm{A}}$ receptor antagonists clearly demonstrate the importance of IPSC duration in controlling excitability in the CNS (Tanelian et al., 1993; Franks and Lieb, 1994). However, more subtle effects of regulating IPSC duration are also likely to be important. Inhibition is critical in the timing of neural circuit activity and can shape oscillations in thalamic, hippocampal, and cortical circuits (van Krosigk et al., 1993; Cobb et al., 1995; Whittington et al., 1995). In hippocampus, for example, single inhibitory neurons with highly branched axons can synchronize the discharge of hundreds of pyramidal cells (Cobb et al., 1995). The frequency of synchronous discharge is limited, in part, by the duration of $\mathrm{GABA}_{\mathrm{A}}$ receptor-mediated IPSCs (Whittington et al., 1995). Dynamic regulation of IPSC duration is thus likely to influence rhythmic activity. Because such regulation can occur locally, in contrast to the global effects of sedative or anesthetic drugs, IPSC regulation by calcineurin may allow individual neurons to adjust their firing in relation to the phase of ongoing circuit oscillations.

By increasing membrane conductance, the IPSC also reduces the neuronal time and space constants, making neuronal firing more selectively responsive to simultaneous excitatory inputs and to those occurring close together in space (Bernander et al., 1991; König et al., 1996). Long-lasting IPSCs will tend to emphasize temporal and spatial coincidence detection, whereas short IPSCs will emphasize summation. Local regulation by calcineurin may therefore influence the selection of inputs to be integrated into the neuronal output, with potentially important effects on signal processing.

\section{REFERENCES}

Angelotti TP, Uhler MD, Macdonald RL (1993) Enhancement of recombinant $\gamma$-aminobutyric acid type A receptor currents by chronic activation of cAMP-dependent protein kinase. Mol Pharmacol 44:1202-1210.

Bernander O, Douglas RJ, Martin KAC, Koch C (1991) Synaptic background activity influences spatiotemporal integration in single pyramidal cells. Proc Natl Acad Sci USA 88:11569-11573.

Bialojan C, Takai A (1988) Inhibitory effect of a marine-sponge toxin, 
okadaic acid, on protein phosphatases. Specificity and kinetics. Biochem J 256:283-290.

Busch C, Sakmann B (1990) Synaptic transmission in hippocampal neurons: numerical reconstruction of quantal IPSCs. Cold Spring Harb Symp Quant Biol 55:69-80.

Chen QX, Wong RKS (1995) Suppression of $\mathrm{GABA}_{\mathrm{A}}$ receptor responses by NMDA application in hippocampal neurones acutely isolated from the adult guinea pig. J Physiol (Lond) 482:353-362.

Cobb SR, Buhl EH, Halasy K, Paulsen O, Somogyi P (1995) Synchronization of neuronal activity in hippocampus by individual GABAergic interneurons. Nature 378:75-78.

Eckstein F (1985) Nucleoside phosphorothioates. Annu Rev Biochem $54: 367-402$

Feigenspan A, Bormann J (1994) Facilitation of GABAergic signaling in the retina by receptors stimulating adenylate cyclase. Proc Natl Acad Sci USA 91:10893-10897.

Franks NP, Lieb WR (1994) Molecular and cellular mechanisms of general anesthesia. Nature 367:607-614.

Frerking M, Wilson M (1996) Saturation of postsynaptic receptors at central synapses? Curr Opin Neurobiol 6:395-403.

Frerking M, Borges S, Wilson M (1995) Variation in GABA mini amplitude is the consequence of variation in transmitter concentration. Neuron 15:885-895.

Hamann H, Desarmenien M, Desaulles E, Bader MF, Feltz P (1988) Quantitative evaluation of the properties of a pyridazinyl GABA derivative (SR 95531) as a $\mathrm{GABA}_{\mathrm{A}}$ competitive antagonist. An electrophysiological approach. Brain Res 442:287-296.

Hashimoto Y, Perrino BA, Soderling TR (1990) Identification of an autoinhibitory domain in calcineurin. J Biol Chem 265:1924-1927.

Jones MV, Westbrook GL (1995) Desensitized states prolong GABA channel responses to brief agonist pulses. Neuron 15:181-191.

Jones MV, Westbrook GL (1996) The impact of receptor desensitization on fast synaptic transmission. Trends Neurosci 19:96-101.

Kano M, Konnerth A (1992) Potentiation of GABA-mediated currents by cAMP-dependent protein kinase. NeuroReport 3:563-566.

Kellenberger S, Malherbe P, Sigel E (1992) Function of the $\alpha 1 \beta 2 \gamma 2 \mathrm{~S}$ $\gamma$-aminobutyric acid type A receptor is modulated by protein kinase $\mathrm{C}$ via multiple phosphorylation sites. J Biol Chem 267:25660-25663.

Klee CB, Draetta GF, Hubbard MJ (1988) Calcineurin. Adv Enzymol 61:149-200.

König P, Engel AK, Singer W (1996) Integrator or coincidence detector? The role of the cortical neuron revisited. Trends Neurosci 19:130-137.

Krishek BJ, Xie X, Blackstone C, Huganir RL, Moss SJ, Smart TG (1994) Regulation of $\mathrm{GABA}_{\mathrm{A}}$ receptor function by protein kinase C phosphorylation. Neuron 12:1081-1095.

Leidenheimer NJ (1996) Effect of PKG activation on recombinant $\mathrm{GABA}_{\mathrm{A}}$ receptors. Brain Res Mol Brain Res 42:131-134.

Leidenheimer NJ, Machu TK, Endo S, Olsen RW, Harris RA, Browning MD (1991) Cyclic AMP-dependent protein kinase decreases $\gamma$ aminobutyric acid $_{\mathrm{A}}$ receptor-mediated ${ }^{36} \mathrm{Cl}^{-}$uptake by brain microsacs. J Neurochem 57:722-725.

Leidenheimer NJ, McQuilkin SJ, Hahner LD, Whiting P, Harris RA (1992) Activation of protein kinase C selectively inhibits the $\gamma$ aminobutyric acid $_{\mathrm{A}}$ receptor: role of desensitization. Mol Pharmacol 41:1116-1123.

Lin Y-F, Browning MD, Dudek EM, Macdonald RL (1994) Protein kinase $\mathrm{C}$ enhances recombinant bovine $\alpha 1 \beta 1 \gamma 2 \mathrm{~L} \mathrm{GABA}_{\mathrm{A}}$ receptor wholecell currents expressed in L929 fibroblasts. Neuron 13:1421-1431.

Maconochie DJ, Zempel JM, Steinbach JH (1994) How quickly can $\mathrm{GABA}_{\mathrm{A}}$ receptors open? Neuron 12:61-71.

Martina M, Mozrzymas JW, Bodekke HWGM, Cherubini E (1996) The calcineurin inhibitor cyclosporin A-cyclophilin A complex reduces desensitization of $\mathrm{GABA}_{\mathrm{A}}$-mediated responses in acutely dissociated rat hippocampal neurons. Neurosci Lett 215:95-98.
Mody I, Tanelian DL, MacIver MB (1991) Halothane enhances tonic neuronal inhibition by elevating intracellular calcium. Brain Res 538:319-323.

Mody I, DeKoninck Y, Otis TS, Soltesz I (1994) Bridging the cleft at GABA synapses in the brain. Trends Neurosci 17:517-525.

Moss SJ, Smart TG, Blackstone CD, Huganir RL (1992) Functional modulation of $\mathrm{GABA}_{\mathrm{A}}$ receptors by cAMP-dependent protein phosphorylation. Science 257:661-665.

Moss SJ, Gorrie GH, Amato A, Smart TG (1995) Modulation of $\mathrm{GABA}_{\mathrm{A}}$ receptors by tyrosine phosphorylation. Nature 377:344-348.

Motulsky HJ, Ransnas LA (1987) Fitting curves to data using nonlinear regression: a practical and nonmathematical review. FASEB J 1:365-374.

Porter NM, Twyman RE, Uhler MD, Macdonald RL (1990) Cyclic AMP-dependent protein kinase decreases $\mathrm{GABA}_{\mathrm{A}}$ receptor current in mouse spinal neurons. Neuron 5:789-796.

Robello M, Amico C, Bucossi G, Rapallino MV, Thellung S (1996) Nitric oxide and $\mathrm{GABA}_{\mathrm{A}}$ receptor function in the rat cerebral cortex and cerebellar granule cells. Neuroscience 74:99-105.

Sigel E, Baur R (1988) Activation of protein kinase C differentially modulates neuronal $\mathrm{Na}^{+}, \mathrm{Ca}^{2+}$, and $\gamma$-aminobutyrate type A channels. Proc Natl Acad Sci USA 85:6192-6196.

Sigel E, Baur R, Malherbe P (1991) Activation of protein kinase C results in down-modulation of different recombinant $\mathrm{GABA}_{\mathrm{A}}$-channels. FEBS Lett 291:150-152.

Sigworth FJ (1980) The variance of sodium current fluctuations at the node of Ranvier. J Physiol (Lond) 307:97-129.

Soltesz I, Mody I (1995) $\mathrm{Ca}^{2+}$-dependent plasticity of miniature inhibitory postsynaptic currents after amputation of dendrites in central neurons. J Neurophysiol 73:1763-1773.

Stelzer A, Shi H (1994) Impairment of $\mathrm{GABA}_{\mathrm{A}}$ receptor function by $N$-methyl-D-aspartate-mediated calcium influx in isolated CA1 pyramidal cells. Neuroscience 62:813-828.

Swope SL, Moss SJ, Blackstone CD, Huganir RL (1992) Phosphorylation of ligand-gated ion channels: a possible mode of synaptic plasticity. FASEB J 6:2514-2523.

Tanelian DL, Kosek P, Mody I, MacIver MB (1993) The role of the $\mathrm{GABA}_{\mathrm{A}}$ receptor/chloride channel complex in anesthesia. Anesthesiology 78:757-776.

Ueno S, Bracamontes J, Zorumski C, Weiss DS, Steinbach JH (1997) Bicuculline and gabazine are allosteric inhibitors of channel opening of the $\mathrm{GABA}_{\mathrm{A}}$ receptor. J Neurosci 17:625-634.

Valenzuela CF, Machu TK, McKernan RM, Whiting P, VanRenterghem BB, Brozowski SJ, Smith GB, Olsen RW, Harris RA (1995) Tyrosine kinase phosphorylation of $\mathrm{GABA}_{\mathrm{A}}$ receptors. Brain Res Mol Brain Res 31:165-172.

van Krosigk M, Bal T, McCormick DA (1993) Cellular mechanisms of a synchronized oscillation in the thalamus. Science 261:361-364.

Wang RA, Cheng G, Kolaj M, Randic M (1995) $\alpha$-Subunit of calcium/ calmodulin-dependent protein kinase II enhances $\gamma$-aminobutyric acid and inhibitory synaptic responses of rat neurons in vitro. J Neurophysiol 73:2099-2106.

Whatley VJ, Mihic SJ, Allan AM, McQuilkin SJ, Harris RA (1994) gamma-Aminobutyric acid $_{\mathrm{A}}$ receptor function is inhibited by microtubule depolymerization. J Biol Chem 29:19546-19552.

Whittington MA, Traub RD, Jefferys JGR (1995) Synchronized oscillations in interneuron networks driven by metabotropic glutamate receptor activation. Nature 373:612-615.

Yakel JL (1997) Calcineurin regulation of synaptic function: from ion channels to transmitter release and gene transcription. Trend Pharmacol Sci 18:124-134.

Zhu WJ, Vicini S (1997) Neurosteroid prolongs GABA $_{\mathrm{A}}$ channel deactivation by altering kinetics of desensitized states. J Neurosci 17:40224031. 